\title{
LA ESCUELA COMO AGENTE DE DESARROLLO HUMANO LOCAL DE LA COMUNIDAD
}

\author{
Esp. Arianne Rodríguez González \\ Universidad de Oriente \\ arianne.rodriguez@uo.edu.cu
}

\author{
MSc. Laura Marín Granados \\ Universidad Estatal de Guayaquil \\ lauraj.marin@outlook.com
}

Palabras claves: desarrollo, desarrollo humano local, comunidad.

Keywords: develop, local human development, community.
Recibido: 20 de enero de 2017

Aceptado: 24 de marzo de 2017

\section{RESUMEN}

El desarrollo de la comunidad es un proceso destinado a crear condiciones de progreso económico y social, con la participación activa de ésta, y la mayor confianza posible en su iniciativa. Por tanto, el desarrollo humano en las comunidades debe ser el proceso que cree riquezas a través de la movilización de recursos humanos. En este artículo se ofrecen dimensiones para el trabajo escuela- comunidad así como indicadores para realizar un diagnóstico en la comunidad, se propone una relación de aquellas agencias y los agentes socializadores que existen en la comunidad van a interactuar entre sí con la finalidad de promover desarrollo humano y con los que se pueden realizar convenios de trabajo para el beneficio de ambos.

\section{ABSTRACT}

Community development is a process designed to create conditions of economic and social progress, with the active participation of the community, and the greatest possible confidence in its initiative. Therefore human development in communities must be the process that creates wealth through the mobilization of human resources. This article offers dimensions for school-community work as well as indicators to make a diagnosis in the community, it proposed a relationship of those agencies and socializing agents that exist in the community are going to interact with each other in order to promote Human development and with which work agreements can be made for the benefit of both. 


\section{INTRODUCCIÓN}

En el transcurso de la vida, la historia contemporánea y su estudio, el concepto de desarrollo humano, ha asumido versiones múltiples. En estudios realizados por varios investigadores, dos de estas versiones han tenido mayor impacto históricosocial. Una centrada fundamentalmente en el aumento de la producción de bienes y servicios basándose en el principio de que un crecimiento del producto interior bruto per cápita (PIB), llevará a una reducción de la pobreza y un mayor bienestar general de la población, concentrándose de esta manera en que este crecimiento no sólo se convierte en medio para alcanzar el desarrollo sino en fin para el mismo. Sin embargo, a finales de los años ochenta esta visión del desarrollo humano es revisada y cuestionada.

Otra manera de ver el desarrollo humano es asumiéndolo desde la concepción de que el desarrollo económico es importante y se revela como condición necesaria, pero no es suficiente, ya que, para que exista desarrollo humano, debe haber un desarrollo general del individuo en todas sus dimensiones.

En la década del noventa se introduce una definición radicalmente nueva de desarrollo humano, al señalar que la verdadera riqueza de una nación está en su gente, y al sostener que el objetivo del desarrollo es crear un ambiente propicio para que los seres humanos disfruten de una vida prolongada, saludable y creativa (PNUD, 1990). Además de considerar el desarrollo, como el derecho a la vida, el acceso a conocimientos y los recursos suficientes, se le asigna una importancia determinante a la libertad política, la creatividad y la dignidad personal.

De esta manera, la teoría del desarrollo humano, ha avanzado desde diversas áreas temáticas referentes al crecimiento económico, la pobreza, la sostenibilidad, la democracia, los derechos humanos, la equidad de género y la libertad cultural. Esta teoría sostiene dos aspectos fundamentales: la formación de capacidades humanas y el uso que la gente hace de las capacidades adquiridas. Este nuevo enfoque de desarrollo humano fundamenta su concepción en la ampliación de las opciones que tienen las personas, aumentando sus capacidades, por tanto se trata de un desarrollo por la gente, para la gente y con la gente, haciéndolas responsables de su desarrollo y de las nuevas generaciones.

\section{DESARROLLO}

En el informe del año 1998 la Comisión Mundial de "Cultura y Desarrollo" de la UNESCO, se expresó... "Un desarrollo disociado de su contexto humano-cultural, es un desarrollo vacío, un desarrollo falaz e incompleto, un desarrollo sin alma". (UNESCO, 1998). En este sentido las comunidades juegan un papel importante por el alcance que tienen en la promoción de desarrollo humano pues desde su misma concepción la comunidad es una agrupación o conjunto de personas que habitan un espacio geográfico delimitado y delimitable, cuyos miembros tienen conciencia de pertenencia o identificación con algún símbolo local y que interaccionan entre sí más intensamente que en otro contexto, operando redes de comunicación, intereses y apoyo mutuo, con el propósito de alcanzar determinados objetivos, satisfacer necesidades, resolver problemas o desempeñar funciones sociales relevantes a nivel local. (Ander-Egg, 2005) 


\section{¿Por qué en las comunidades?}

Es en una comunidad donde se ponen en juego relaciones, actitudes y comportamientos de los sujetos que la habitan. Donde existen aspectos comunes, compartidos: historia y cultura, intereses, necesidades, problemas, expectativas socialmente construidos por los miembros del grupo. Es donde se recrea un espacio y un tiempo y las relaciones sociales son habituales y frecuentes, muchas veces cara a cara. Donde se forma el sentido de pertenencia a la comunidad. Se considera es un nivel de integración mucho más concreto que el de otras formas colectivas de organización social, tales como la clase social, la etnia, la religión o la nación. Y sobre todo donde existe una vinculación emocional compartida.

Es por ello que el desarrollo de la comunidad es un proceso destinado a crear condiciones de progreso económico y social para toda la comunidad, con la participación activa de ésta, y la mayor confianza posible en su iniciativa. Por tanto el desarrollo humano en las comunidades debe ser el proceso que cree riquezas a través de la movilización de recursos humanos, de capitales físicos y naturales para generar bienes y servicios transables. Debe concretarse como una estrategia común que se revele al servicio del individuo y que su promoción la realicen los agentes y agencias locales para el bien de la comunidad en general.

Teniendo en cuenta los elementos antes aportados, se asume la definición que brinda Orduña (2000), sobre el desarrollo comunitario local donde lo visualiza como un proceso global, integrado y sostenible de cambio social; protagonizado por la comunidad, organizada en un territorio bien definido, que participa activamente en el aprovechamiento de los recursos locales: humanos, materiales, naturales, financieros y sociales, para la mejora de sus condiciones de vida.

En análisis del término desarrollo humano comunitario o local se encuentran rasgos que lo defines entre los que podemos destacar:

- Es un proceso educativo destinado a lograr cambios cualitativos en las actitudes y comportamientos de la población.

- Es una técnica de acción social. Por tanto, necesita de la intervención o colaboración de agentes con cierto grado de especialización.

- Se dirige a aquellas comunidades en proceso de desarrollo

- Su objetivo primordial consiste en la consecución del bienestar social; y, consecuentemente, la mejora de la calidad de vida de la población o comunidad objeto

- Requiere la participación voluntaria, consciente y responsable de los individuos en la resolución de sus propios problemas.

¿Cómo puede la escuela convertirse en agente de desarrollo humano local y de mejora de calidad de vida, desde su relación escuela -comunidad?

El carácter socio-estructural inherente a la sociedad cubana convierte la política educacional en política social claramente definida. Sin embargo, no se resuelve aun satisfactoriamente, el modelo concreto en que el conjunto de factores sociales de la comunidad contribuye a la formación de niños y adolescentes, confiándole fundamentalmente a la escuela dicha tarea; lo que denota que en la interacción escuela-comunidad se carece aún de un estudio profundo. Por ende con relación a la formación ciudadana, tampoco la sociedad más próxima al niño y al joven ha cumplido su cuota de responsabilidad lo que supone conocer cómo el intercambio 
con la comunidad puede contribuir al perfeccionamiento del proceso docente educativo y a elevar la calidad de la educación.

Es necesario enfocar el sistema integral la interacción escuela -comunidad, sin desconocer su independencia relativa, en tanto tienen funciones específicas como instituciones socializadoras en su labor educativa, la escuela como el medio para alcanzar la más alta síntesis de los valores educativos a través del conocimiento organizado, sistemáticamente dirigido como proceso intelectual y afectivo para la formación del individuo y orientado en función de la vida cotidiana. Y la comunidad, como grupo social heterogéneo, que se caracteriza por su asentamiento en un territorio determinado, compartido entre todos sus miembros, donde tienen lugar y se intensifican de un modo específico las interacciones e interinfluencias sociales, en torno a la satisfacción de las necesidades de la vida cotidiana.

El primer aspecto que se considera necesario para promover el desarrollo humano local desde la escuela es realizar un diagnóstico acertado de la comunidad. Donde se abarque todos los aspectos de la vida de la Comunidad: economía, educación, salud, recreación y deporte, vivienda, familia, organizaciones sociales, identidad local, etc.

Carvajal (2011) considera que en los procesos sociales se deben realizar diagnósticos participativos ya que persiguen los siguientes objetivos:

- Conocer a fondo una realidad social y ser una base firme para la elaboración del Plan de Desarrollo

- Generar en la comunidad procesos de organización, concientización y movilización social

- Construir actores sociales y fortalecer el tejido comunitario.

- Capacitar a la comunidad en diagnóstico, investigación social, elaboración de proyectos, participación, etc.

- Fortalecer el liderazgo comunitario.

- Constituir un espacio de encuentro y de discusión de los diferentes actores de la comunidad; de tal forma que supere las diferencias internas y genere un proceso de consenso y concertación.

- Ser una herramienta pedagógica para la enseñanza de la realidad local en los diferentes planteles educativos y comunitarios.

- Lograr que la comunidad se apropie de la información resultante del estudio y la convierta en herramienta para la toma de decisiones, como también para afianzar su identidad.

- La metodología del diagnóstico participativo es más apropiada donde: el grupo es una comunidad y el trabajo es hecho por personas de la comunidad. 
¿Cómo realizar un diagnóstico, sobre la base de qué indicadores?

\begin{tabular}{|l|l|}
\hline $\begin{array}{l}\text { Indicadores } \\
\text { dimensiones }\end{array}$ & \multicolumn{1}{|c|}{ Aspectos } \\
\hline Contexto de la localidad & Localización geográfica \\
\hline Dimensión Ambiental & $\begin{array}{l}\text { Geología-clima, Geomorfología e Hidrología, Riesgos } \\
\text { naturales e Impacto ambiental prevalente }\end{array}$ \\
\hline Dimensión Geográfica & $\begin{array}{l}\text { Procesos de poblamiento Composición espacial de la } \\
\text { población }\end{array}$ \\
\hline Dimensión Económica & $\begin{array}{l}\text { Composición sectorial de la producción Perspectivas } \\
\text { de los negocios en la localidad, Costos sociales } \\
\text { asociados a la dinámica económica de la localidad } \\
\text { Comercialización de productos agrícolas }\end{array}$ \\
\hline Dimensión Social & $\begin{array}{l}\text { Análisis de la calidad de vida, Análisis de las } \\
\text { perspectivas de desarrollo humano } \\
\text { institucional: salud, educación, cultural, recreativa), } \\
\text { Análisis de los servicios comunales }\end{array}$ \\
\hline $\begin{array}{l}\text { Dimensión } \\
\text { Política }\end{array}$ & $\begin{array}{l}\text { Análisis de los problemas de convivencia social, } \\
\text { Participación comunitaria, Espacios de participación }\end{array}$ \\
\hline Dimensión Institucional & \begin{tabular}{l} 
Presencia de órganos y organismos institucionales \\
\hline
\end{tabular}
\end{tabular}

La escuela debe realizar una valoración certera de aquellas agencias y los agentes socializadores que existen en la comunidad van a interactuar entre sí con la finalidad de promover desarrollo humano y realizar convenios de trabajo, nos referimos entre otras a:

- Industrias y/o centros de producción y servicios principales del territorio.

- Líderes empresariales y laborales

- Organizaciones políticas y de masas

- Otras Instituciones educativas de la localidad

- Dirección política- administrativa del Consejo Popular, circunscripción, barrio y cuadra

- Centros de salud

- Centros Culturales

- Centros Deportivos y recreativos

- Centros Religiosos

- Otras instituciones e instalaciones sociales existentes en el territorio

- Centros Turísticas

- Casa de abuelos

- Casa de niños sin amparo filial

- Asociación de combatientes

- Lugares históricos (Hechos de la historia local, tarjas y monumentos)

\section{CONCLUSIONES}

El vínculo con la comunidad se expresa en desarrollo humano local, pues constituye es un proceso de concertación entre los agentes -sectores y fuerzas- que interactúan en un territorio determinado y que sirven para impulsar, con la participación permanente, creadora y responsable de ciudadanos y ciudadanas un 
proyecto común de desarrollo, que va a implicar la generación de crecimiento económico, equidad, cambio social y cultural, sustentabilidad ecológica, enfoque de género, calidad y equilibrio espacial y territorial. Todo ello con el fin de elevar la calidad de vida de cada familia, ciudadano y ciudadana que vive en ese territorio, contribuir al desarrollo del país y enfrentar adecuadamente los retos de la globalización y las transformaciones de la economía internacional. 


\section{REFERENCIAS BIBLIOGRÁFICAS}

Ander-Egg, E. (2005). Metodología y práctica del desarrollo de la comunidad. $2^{\mathrm{a}}$. Edición. Editorial Lumen Humanitas. Argentina.

Carvajal, A. (2011). Apuntes sobre Desarrollo Comunitario. Primera Edición Digital. Eumed.net, Universidad de Málaga. España.

Carvajal, A. (2011). Manual Básico para Agentes de Desarrollo Local y otros actores. Primera Edición Digital. Eumed.net, Universidad de Málaga. España

Centro Latinoamericano de Capacitación y Desarrollo de los Gobiernos Locales. IULA/CELCADEL. (1993). El Municipio como Promotor del Desarrollo Económico Local. Cuaderno de Desarrollo Local, Nº 13. Ecuador.

Nogueiras, L. (1996). La práctica y la teoría del desarrollo comunitario: descripción de un modelo. Narcea. Madrid.

Orduña, G. (2000). Apuntes sobre Desarrollo Comunitario. Primera Edición Digital. Eumed.net, Universidad de Málaga. España.

PNUD. (1990). PNUD, ASDI \& Agencia de Cooperación para el desarrollo. Temas que no pueden faltar en los Planes de Desarrollo. 